\title{
ANALISIS TERHADAP KEMANDIRIAN MAHASISWA DALAM BELAJAR STATISTIKA
}

\author{
Louise M. Saija \\ Fakultas keguruan dan Ilmu Pendidikan \\ Universitas Advent Indonesia \\ louise_saija@yahoo.com
}

\begin{abstract}
Abstrak: Penelitian ini bertujuan untuk mengetahui bagaimana motivasi dan pembelajaran regulasi diri dan faktor manakah yang paling dominan pada motivasi dan strategi regulasi diri mahasiswa dalam belajar statistika. Sampel pada penelitian ini adalah 202 mahasiswa peserta kelas statistika pada program studi manajemen dan akuntansi di Universitas Advent Indonesia. Instrumen yang digunakan untuk mengukur strategi motivasi belajar adalah instrumen baku MSLQ (Motivated Strategies for Learning Questionaire) dari Pintrich dan DeGroot. Faktorfaktor dari motivasi dan pembelajaran regulasi diri adalah: Self Efficacy, Intrisic Factor, Test Anxiety, Cognitive Strategy Use, Self Regulation. Metode penelitian yang digunakan adalah metode kuantitatif dengan analisa deskriptif dan analisa faktor. Hasil penelitian menunjukkan bahwa secara rerata, mahasiswa fakultas ekonomi di Universitas Advent Indonesia memiliki Self-Efficacy, Intrisic Value, Cognitive Strategy Use dan Self-Regulation yang baik, serta Test Anxiety yang cukup baik. Selanjutnya ditemukan bahwa faktor Cognitive strategy use paling dominan dalam motivasi dan strategi regulasi diri mahasiswa fakultas ekonomi Universitas Advent Indonesia dalam belajar statistika.
\end{abstract}

Kata Kunci: Motivasi dan pembelajaran regulasi diri, MSLQ, statistik

Abstract: This research aimed to find out the student's motivation and self-regulated learning, and which is the dominant factor in the student's motivation and self-regulated learning. The respondents are 202 students in statistics classes majoring mangement and accounting in Universitas Advent Indonesia. The instrument used is the standardized instrument named MSLQ (Motivated Strategies for Learning Questionaire) from Pintrich and DeGroot. The factors of motivation and self-regulated learning is: Self Efficacy, Intrisic Factor, Test Anxiety, Cognitive Strategy Use, Self Regulation. The method used in this research is quantitative method with descriptive analysis and factor analysis. The result show that averagely the economic students in Universitas Advent Indonesia has good self-efficacy, Intrisic Value, Cognitive Strategy Use and Self-regulation, and worth Test Anxiety. Morefurther, it is found that the Cognitive strategy use is the most dominant factor in motivation and self-regulated learning of economic students of Universitas Advent Indonesia in learning statistics.

Keywords: Motivation and self-regulated learning, MSLQ, statistics.

\section{PENDAHULUAN}

Matematika adalah ilmu dasar yang sangat penting. Hal ini terbukti dengan adanya mata pelajaran matematika pada kurikulum pendidikan dasar dan menengah, bahkan pada beberapa program studi di perguruan tinggi. Demikian juga dengan salah satu cabang ilmu matematika, yaitu statistika. Statistika juga sudah diperkenalkan pada siswa sejak sekolah dasar. Sampai pada tingkat perguruan tinggi, ada banyak program studi yang mencantumkan mata kuliah statistika pada kurikulumnya, walau program studi tersebut tergolong pada ilmu sosial. Dua di 
antaranya adalah program studi akuntansi dan program studi manajemen. Matematika penting dipelajari oleh mahasiswa program studi akuntansi karena unsur-unsur matematika banyak dimuat dalam ilmu akuntansi (Siagian, 2013), dan juga dipelajari oleh mahasiswa program studi manajemen.

Statistika adalah cabang ilmu matematika yang mempelajari tentang cara pengumpulan, pengolahan dan analisis data untuk dapat mengambil keputusan yang tepat. Oleh karenanya statistika perlu dipelajari oleh setiap individu yang melakukan pengumpulan data, pengolahan dan analisis data, dan pada akhirnya dapat mengambil keputusan dengan tepat berdasarkan data yang dimilikinya. Statistika terbagi dalam dua bagian besar, yaitu statistik deskriptif dan statistik inferensial. Statistik deskriptif mempelajari tentang cara mendeskripsikan satu variabel, ukuran pemusatan dan variabilitasnya, juga tentang hubungan atau peranan dua variabel. Sedangkan Statistik inferensial mempelajari tentang bagaimana cara mengambil keputusan untuk populasi data berdasarkan pada data sampel dengan satu tingkat kepercayaan tertentu. Jadi statistika perlu dipahami oleh mahasiswa, secara khusus dalam upaya mengolah data penelitian yang dilakukan mahasiswa, paling sedikit pada tugas akhir mereka.

Mahasiswa perlu melatih dirinya untuk dapat belajar dengan baik untuk semua mata kuliah yang tercantum dalam kurikulum prodi yang dipilih. Mereka perlu menunjukkan kemandirian dalam belajar. Mereka memerlukan motivasi dan pembelajaran regulasi diri yang baik dalam belajar, karena hal tersebut akan mempengaruhi hasil belajar mahasiswa tersebut. Dan hal-hal tersebut juga berlaku dalam belajar statistika. Kemandirian belajar atau pembelajaran regulasi diri atau self regulated learning memberi perhatian pada aplikasi dari model-model regualsi dan regulasi diri yang umum terhadap masalah belajar, terutama pada konteks akademik. Kemandirian belajar adalah suatu proses yang aktif dan kronstruktif dimana pembelajar menetapkan tujuan mereka dalam belajar dan kemudian mencoba untuk melakukan monitor, regulasi, dan pengendalian terhadap kognisi mereka, juga sikap dan motivasi (Wolters et al., 2003). Selanjutnya, motivasi adalah suatu penjelasan terhadap sebab yang terdapat dalam diri seseorang untuk melakukan suatu hal, dan tetap melakukannya (Novia, 2013). Ada tiga indikator motivasi dalam belajar yang dikemukakan oleh Pintrich (1991), yaitu: Value component, Expectancy component, dan affective component. Value component adalah komponen yang menunjukkan tentang keyakinan seorang pembelajar tentang nilai atau pentingnya tugas belajar. Dan Expectancy componen adalah komponen yang menunjukkan tentang keyakinan seorang pembelajar tentang kemampuan dirinya, juga keterampilannya dalam mengerjakan tugas dalam belajar. Sedangkan affective component adalah komponen 
yang menunjukkan tentang perasaan seorang pembelajar tentang dirinya, atau tentang reaksi emosional yang dimilikinya dalam mengerjakan tugas belajar.

Pintrich dan DeGroot (1990) memasukkan factor test anxiety atau kecemasan ujian sebagai salah satu faktor regulasi diri, tetapi permasalahan yang ditemukan dari penelitian sebelumnya adalah: Banyak mahasiswa yang cemas terhadap statistika dan mempengaruhi hasil belajar statistika (Williams, 2013). Permasalahan lainnya adalah motivasi belajar statistik yang masih rendah (Afifah dan Wicaksana, 2014), padahal semakin tinggi motivasi dari pembelajar, maka pencapaian belajarnya juga akan semakin tinggi (Ayundawati dkk, 2016). Dalam penelitian ini akan dicari tahu bagaimana motivasi dan pembelajaran regulasi diri mahasiswa jurusan manajemen dan akuntansi Universitas Advent Indonesia, serta dan faktor manakah yang paling dominan pada motivasi dan strategi regulasi diri mahasiswa dalam belajar statistika.

\section{METODE PENELITIAN}

Metode penelitian yang digunakan adalah metode kuantitatif dengan analisa deskriptif dan analisa faktor. Dalam analisis deskriptif, maka untuk menarik kesimpulan tentang faktorfaktor pada MSLQ maka untuk setiap pernyataan yang ada tanggapan responden dibagi dalam lima kelas dengan panjang kelas $=(7-1) / 5=1,2$. Kategori tanggapan $(\mathrm{X})$ responden adalah: Sangat buruk $(1 \leq X \leq 2,2)$, Buruk $(2,2<X \leq 3,4)$, Cukup baik $(3,4<X \leq 4,6)$, Baik $(4,6<X$ $\leq 5,8)$, Sangat baik $(5,8<X \leq 7)$. Selanjutnya dalam analisis factor, dilakukan tahapan analisis terhadap Correlation Matrix, KMO dan Bartlett's test, Tabel anti image matrices, Tabel communalities, Tabel total variance explained, Tabel component matrix, Tabel rotated matrix dan Tabel Component Transformation Matrix (jika ada lebih dari satu component). Responden pada penelitian ini adalah 202 mahasiswa peserta kelas statistika pada prodi akuntansi dan prodi manajemen Fakultas Ekonomi Universitas Advent Indonesia pada tahun ajaran 20172018.

Instrumen yang digunakan untuk mengukur strategi motivasi belajar adalah instrumen baku MSLQ (Motivated Strategies for Learning Questionaire) dari Pintrich dan DeGroot (1990). Instrumen ini terdiri dari 44 pernyataan (dapat dilihat pada Lampiran 1) berskala 7, angka 1 berarti: "sama sekali tidak benar untuk saya" dan angka 7 berarti: "sangat benar untuk saya". Pernyataan-pernyataan tersebut dibagi dalam 5 faktor, yaitu: Self Efficacy (pernyataan no 2, 6, 8, 9,11,13,16,18,19), Intrisic Factor (pernyataan nomor 1, 4, 5, 7, 10, 14, 15, 17, 21),

Test Anxiety (pernyataan nomor 3, 12, 20, 22), Cognitive Strategy Use (pernyataan nomor 23, 
24, 26, 28, 29, 30, 31, 34, 36, 39, 41, 42, 44), dan Self Regulation (pernyataan nomor 25, 27, $32,33,35,37,38,40,43)$.

\section{HASIL PENELITIAN}

\section{A. Hasil Analisis Deskriptif}

Analisis deskriptif sederhana ini dilakukan berdasarkan tabel di bawah ni

\begin{tabular}{|c|c|c|c|c|c|c|c|}
\hline & N & Minimum & Maximum & Sum & Mean & Std. Deviation & Variance \\
\hline SE & 202 & 14 & 59 & 8744 & 43,29 & 8,143 & 66,315 \\
IV & 202 & 15 & 62 & 9368 & 46,38 & 7,466 & 55,748 \\
TA & 202 & 4 & 28 & 3363 & 16,65 & 5,373 & 28,866 \\
CSU & 202 & 19 & 89 & 12835 & 63,54 & 11,864 & 140,757 \\
SR & 202 & 21 & 55 & 8625 & 42,70 & 6,315 & 39,874 \\
Valid N (listwise) & 202 & & & & & & \\
\hline
\end{tabular}

1. Faktor Self-Efficacy (SE)

Nilai mean untuk faktor Self-Efficacy adalah 43,29. Mengingat bahwa ada 9 pernyataan untuk faktor ini maka rerata tanggapan per pernyataan adalah 43,29/9=4,81. Hal tersebut berarti secara rerata mahasiswa fakultas ekonomi Universitas Advent Indonesia memiliki SelfEfficacy yang baik.

\section{Faktor Intrisic Value}

Nilai mean untuk faktor Intrisic Value adalah 46,38. Mengingat bahwa ada 9 pernyataan untuk faktor ini maka rerata tanggapan per pernyataan adalah 46,38 / $9=5,15$. Hal tersebut berarti secara rerata mahasiswa fakultas ekonomi Universitas Advent Indonesia memiliki Intrisic Value yang baik.

\section{Faktor Test Anxiety}

Nilai mean untuk faktor Test Anxiety adalah 16,65. Mengingat bahwa ada 4 pernyataan untuk faktor ini maka rerata tanggapan per pernyataan adalah 16,65/4 =4,16. Hal tersebut berarti secara rerata mahasiswa fakultas ekonomi Universitas Advent Indonesia memiliki Test Anxiety yang cukup baik.

\section{Faktor Cognitive Strategy Use}

Nilai mean untuk faktor Cognitive Strategy Use adalah 63,54. Mengingat bahwa ada 13 pernyataan untuk faktor ini maka rerata tanggapan per pernyataan adalah 63,54 / $13=4,89$. Hal tersebut berarti secara rerata mahasiswa fakultas ekonomi Universitas Advent Indonesia memiliki Cognitive Strategy Use yang baik. 


\section{Faktor Self-Regulation}

Nilai mean untuk faktor Self-Regulation adalah 42,70. Mengingat bahwa ada 9 pernyataan untuk faktor ini maka rerata tanggapan per pernyataan adalah 42,70/9=4,74. Hal tersebut berarti secara rerata mahasiswa fakultas ekonomi Universitas Advent Indonesia memiliki Self-Regulation yang baik.

\section{B. Hasil Analisis Faktor}

Analisis faktor secara bertahap pada SPSS output untuk menemukan faktor manakah yang paling dominan dalam motivasi dan strategi regulasi diri mahasiswa fakultas ekonomi Universitas Advent Indonesia dalam belajar statistika.

1. Tabel Matriks Korelasi

\begin{tabular}{|ll|r|r|r|r|r|}
\hline & Zscore(SE) & Zscore(IV) & Zscore(TA) & Zscore(CSU) & Zscore(SR) \\
\hline Correlation & Zscore(SE) & 1,000 &, 627 &,- 216 &, 594 &, 374 \\
& Zscore(IV) &, 627 & 1,000 &,- 079 &, 535 &, 425 \\
& Zscore(TA) &,- 216 &,- 079 & 1,000 &,- 029 &, 151 \\
& Zscore(CSU) &, 594 &, 535 &,- 029 & 1,000 &, 605 \\
& Zscore(SR) &, 374 &, 425 &, 151 &, 005 &, 000 \\
\hline Sig. (1-tailed) & Zscore(SE) & &, 000 &, 000 &, 000 \\
& Zscore(IV) &, 000 & &, 132 &, 000 &, 000 \\
& Zscore(TA) &, 001 &, 132 &, 340 &, 016 \\
& Zscore(CSU) &, 000 &, 000 &, 340 &, 000 \\
& Zscore(SR) &, 000 &, 000 &, 016 &, 000 &, \\
\hline
\end{tabular}

a. Determinant $=, 202$

Dari tabel di atas terlihat bahwa kelima faktor saling berhubungan atau berkorelasi satu sama lain. Sebagai contoh: Nilai 0,627 menunjukkan ada korelasi antara faktor Self Efficacy dan Intrisic Value, sifat korelasi positif dan kuat, dengan nilai significant $0,000<0,05$.

\section{Tabel KMO and Bartlett's Test}

\begin{tabular}{|c|c|c|}
\hline Kaiser-Meyer-Olkin Me & Sampling Adequacy. & ,721 \\
\hline \multirow{3}{*}{ Bartlett's Test of Sphericity } & Approx. Chi-Square & 317,892 \\
\hline & df & 10 \\
\hline & Sig. &, 000 \\
\hline
\end{tabular}

Berdasarkan tabel di atas, nilai Chi-square adalah 317,892 dengan nilai sig. $=0,000<$ 0,05, artinya dapat dilakukan analisis komponen utama. Nilai Kaiser-Meyer-Olkin $(\mathrm{KMO})=$ 
0,721, sehingga layak dilakukan analisis faktor atau variabel-variabel dapat dianalisis lebih lanjut.

\section{Tabel Anti Image Matrices}

\begin{tabular}{|c|c|c|c|c|c|c|}
\hline & & Zscore(SE) & Zscore(IV) & Zscore(TA) & Zscore(CSU) & Zscore(SR) \\
\hline \multirow{5}{*}{ Anti-image Covariance } & Zscore(SE) & ,483 &,- 231 &, 154 &,- 170 &,- 001 \\
\hline & Zscore(IV) &,- 231 &, 552 &,- 006 &,- 075 &,- 087 \\
\hline & Zscore(TA) &, 154 &,- 006 & 891 &, 005 &,- 160 \\
\hline & Zscore(CSU) &,- 170 &,- 075 &, 005 & ,466 &,- 245 \\
\hline & Zscore(SR) &,- 001 &,- 087 &,- 160 &,- 245 &, 588 \\
\hline \multirow{5}{*}{ Anti-image Correlation } & Zscore(SE) &, $709^{\mathrm{a}}$ &,- 447 & ,234 &,- 358 &,- 002 \\
\hline & Zscore(IV) &,- 447 &, $779^{\mathrm{a}}$ &,- 008 &,- 149 &,- 153 \\
\hline & Zscore(TA) &, 234 &,- 008 &, $424^{\mathrm{a}}$ & ,008 &,- 221 \\
\hline & Zscore(CSU) &,- 358 &,- 149 & ,008 &, $732^{\mathrm{a}}$ &,- 467 \\
\hline & Zscore(SR) &,- 002 &,- 153 &,- 221 &,- 467 &, $710^{\mathrm{a}}$ \\
\hline
\end{tabular}

Pada tabel di atas, perhatikan nilai2 MSA (yang bertanda a), karena untuk Zscore(TA) nilai MSA adalah 0,424 $<0,5$ maka variabel Zscore(TA) harus dikeluarkan dahulu dan dilakukan analisis faktor sekali lagi.

4. Tabel KMO and Bartlett's Test (setelah variabel TA dikeluarkan)

\begin{tabular}{|c|c|c|}
\hline \multicolumn{2}{|c|}{ Kaiser-Meyer-Olkin Measure of Sampling Adequacy. } & ,734 \\
\hline \multirow{3}{*}{ Bartlett's Test of Sphericity } & Approx. Chi-Square & 295,438 \\
\hline & df & 6 \\
\hline & Sig. & 000 \\
\hline
\end{tabular}

Tabel di atas menunjukkan nilai Kaiser-Meyer-Olkin $(\mathrm{KMO})=0,734$ adalah lebih besar dari nilai KMO sebelum variabel TA dikeluarkan. Hal ini berarti pengurangan variabel Zscore(TA) adalah cukup beralasan atau keempat variabel yang sisa: Zscore(SE), Zscore(IV), Zscore(CSU), Zscore(SR) layak untuk digunakan sebagai variabel-variabel dalam analisis faktor selanjutnya. 
5. Tabel Anti Image Matrices (setelah variabel TA dikeluarkan)

\begin{tabular}{|cc|c|c|c|c|}
\hline & & Zscore(SE) & Zscore(IV) & Zscore(CSU) & Zscore(SR) \\
\hline \multirow{4}{*}{ Anti-image Covariance } & Zscore(SE) &, 511 &,- 243 &,- 181 &, 029 \\
& Zscore(IV) &,- 243 &, 552 &,- 075 &,- 093 \\
& Zscore(CSU) &,- 181 &,- 075 &, 466 &,- 256 \\
& Zscore(SR) &, 029 &,- 093 &,- 256 &, 618 \\
\hline \multirow{4}{*}{ Anti-image Correlation } & Zscore(SE) &, $718^{\mathrm{a}}$ &,- 458 &,- 370 &, 052 \\
& Zscore(IV) &,- 458 &, $770^{\mathrm{a}}$ &,- 149 &,- 158 \\
& Zscore(CSU) &,- 370 &,- 149 &, $722^{\mathrm{a}}$ &,- 477 \\
& Zscore(SR) &, 052 &,- 158 &,- 477 &, $729^{\mathrm{a}}$ \\
\hline
\end{tabular}

a. Measures of Sampling Adequacy(MSA)

Tabel di atas menunjukkan bahwa nilai MSA untuk keempat variabel sudah $>0,5$, sehingga analisis dapat dilanjutkan.

\section{Tabel Communalities}

\begin{tabular}{|c|c|c|}
\hline & Initial & Extraction \\
\hline Zscore(SE) & 1,000 &, 661 \\
Zscore(IV) & 1,000 &, 652 \\
Zscore(CSU) & 1,000 &, 734 \\
Zscore(SR) & 1,000 &, 540 \\
\hline
\end{tabular}

Extraction Method: Principal Component

Analysis.

Tabel di atas memperlihatkan bahwa keempat variabel memiliki nilai communalities yang lebih besar dari 0,5, hal ini berarti bahwa kseluruhan variabel yang digunakan memiliki memiliki hubungan yang kuat dengan faktor yang terbentuk (semakin besar nilai communalities menunjukkan hubungan yang semakin baik). Nilai-nilai itu juga menunjukkan persentase kontribusi variabel terhadap faktor yang terbentuk, dalam penelitian ini adalah faktor motivational and self-regulated learning. Jadi kontribusi terbesar pada motivasi dan strategi regulasi diri terletak pada variabel Cognitive Strategy Use (CSU), yaitu sebesar 73,4\%. 
7. Tabel Total Variance Explained

\begin{tabular}{|c|c|c|c|c|c|c|}
\hline \multirow{2}{*}{ Component } & \multicolumn{4}{|c|}{ Initial Eigenvalues } & \multicolumn{3}{c|}{ Extraction Sums of Squared Loadings } \\
\cline { 2 - 7 } & Total & \% of Variance & Cumulative \% & Total & \% of Variance & Cumulative \% \\
\hline 1 & 2,586 & 64,662 & 64,662 & 2,586 & 64,662 & 64,662 \\
2 &, 696 & 17,409 & 82,071 & & & \\
3 &, 413 & 10,318 & 92,389 & & & \\
4 &, 304 & 7,611 & 100,000 & & & \\
\hline
\end{tabular}

Extraction Method: Principal Component Analysis.

Tabel Total Variance Explained menunjukkan besarnya persentase variance (keragaman) total yang dapat diterangkan oleh keragaman faktor-faktor yang terbentuk dengan memperhatikan komponen yang memiliki eigenvalue $>1$ saja. Jadi dari tabel di atas terlihat bahwa komponen 1 saja yang diperhatikan dan $64,662 \%$ keragaman total dapat diterangkan.

\section{Tabel Component Matrix}

\begin{tabular}{|c|c|}
\hline \multirow{2}{*}{} & Component \\
\cline { 2 - 2 } & 1 \\
\hline Zscore(SE) &, 813 \\
Zscore(IV) &, 807 \\
Zscore(CSU) &, 857 \\
Zscore(SR) &, 735 \\
\hline
\end{tabular}

Extraction Method: Principal

Component Analysis.

a. 1 components extracted.

Tabel Component Matrix menunjukkan besarnya korelasi tiap variabel dalam faktor yang terbentuk (loading factor). Terlihat bahwa Zscore(CSU) memiliki korelasi tertinggi yaitu 0,857, artinya CSU (Cognitive Strategi Use) atau strategi kognitif yang digunakan memberi pengaruh yang paling kuat terhadap motivasi dan strategi regulasi diri mahasiswa fakultas ekonomi Universitas Advent Indonesia dalam belajar Statistika.

\section{KESIMPULAN}

Kesimpulan yang diperoleh sebagai hasil penelitian terhadap 202 mahasiswa prodi akuntansi dan manajemen Fakultas Ekonomi Universitas Advent Indonesia adalah: 
1. Secara rerata, mahasiswa fakultas ekonomi di Universitas Advent Indonesia memiliki SelfEfficacy, Intrisic Value, Cognitive Strategy Use dan Self-Regulation yang baik, serta Test Anxiety yang cukup baik.

2. CSU (Cognitive Strategi Use) atau strategi kognitif yang digunakan memberi pengaruh yang paling kuat terhadap motivasi dan strategi regulasi diri dalam belajar statistik. Jadi, CSU (Cognitive Strategi Use) atau strategi kognitif yang digunakan merupakan faktor yang paling dominan dalam motivasi dan strategi regulasi diri mahasiswa dalam fakultas ekonomi Universitas Advent Indonesia dalam belajar statistika secara mandiri.

\section{DAFTAR PUSTAKA}

Afifah, S. N. \& Wicaksana, E. J. (2014). Persepsi Mahasiswa tentang Mata Kuliah Statistik Serta Pengaruhnya terhadap Prestasi Belajar Statistik Mahasiswa IKIP PGRI Madiun. Jurnal CARE Volume 02 Nomor 1

Artini, D. A., Kirya, K., Suwendra, D. (2014). Faktor-Faktor yang Mempengaruhi Keputusan Mahasiswa dalam Memilih Jurusan di Fakultas Ekonomi dan Bisnis (FEB) Universitas Pendidikan Ganesha (UNDIKSHA) sebagai Tempat Kuliah. Singaraja

Artino, A. R. Jr. (2005). Review of the Motivated Strategies for Learning Questionnaire. University of Connecticut.

Ayundawati, D. dkk (2016). Influence of Strategy of Learning and Achievement Motivation of Learning Achievement Class VIII Students of State Junior High School in District Blitar. Journal of Education and Practice www.iiste.org ISSN 2222-1735 (Paper) ISSN 2222-288X (Online) Vol.7, No.32, 2016109

Aziz , A. (2013). Hubungan Dukungan Sosial dengan Self Regulated Learning pada Siswa SMA Yayasan Perguruan Bandung Tembung. Universitas Medan Area.

Chikaodinaka. A. O., Okafor, G., Chika, N. (2015). Effect of Self Regulated Learning Approach on Junior Secondary School Students' Achievment in Basic Science. Ebonyi State University.

Feiz .P., Hooman, H.A., kooshki, Sh. 2015. Assesing the Motivated Strategies for Learning Questionnaire (MSQL) in Iranian students: Construct Validity and Reliability. Islamic Azad University.

Hsiang-Yung-Feng, Jin-Jin Fan, Hui-Zhen Yang. (2013). The Relationship Of Learning Motivation And Achievment In Efl: Gender as an intermediated variable. National United University, National Pingtung Institut of Commerce, Taiwan.

Makki, A. (2010). Hubungan Antara Self-Regulated Learning dengan Prestasi Belajar Siswa SMP Bina Amal Bekasi. Universitas Islam Negri Syarif Hidayatullah Jakarta.

Nausheen, Munaza. (2016). An Adaption of The Motivated Strategies for Learning Quetionnaire (MSLQ) for Postgraduated Students in Pakistan: Results of an Exploratory Factor Analysis. University of the Punjab, Lahore, Pakistan.

Novia, Sheily. 2013. Pengaruh Penggunaan Teknik Ice Breaker terhadap Motivasi Belajar Siswa pada Pembelajaran IPS (Studi Eksperimen Kuasi Pada Siswa Kelas VII SMPN 1 Bandung. Universitas Pendidikan Indonesia.

Pintrich, P. R. \& De Groot, E. V. (1990). Motivation and Self-Regulated Learning Components of Classroom Academic Performance. Journal of Educational Psychology, CSU (Cognitive Strategi Use) atau strategi kognitif yang digunakanol. 82, No. 1, 33-40. 
Siagian, P. 2013. Pengaruh Matematika terhadap Motivasi dan Prestasi Belajar Matematika Jurusan Akutansi Universitas Bina Nusantara. BINUS University

Taylor, R. T. 2012. Review of the Motivated Strategies for Learning Questionnaire (MSLQ) Using Reliability Generalization Techniques to Assess Scale Reliability. Auburn, Alabama.

William, A. S. 2013. Worry, Intolerance of Uncertainity, and Statistics Anxiety. Texas Tech University.

Wolters, C. A. (2003). Assesing Academic Self-regulated Learning. University of Housten, University of Michigan, Easstern Michigan University. 